\title{
Accuracy analysis of stowing computations for securing non-standard cargoes on ships according to IMO CSS Code
}

\author{
Jerzy Kabaciński \\ Bogusz Wiśnicki, Ph. D. \\ Maritime University of Szczecin
}

\begin{abstract}
The article takes up a subject of effectiveness of securing arrangements while stowing non-standard cargoes on ships. Accuracy analysis of stowing calculations was based on procedures proposed by Code of Safe Practice for Cargo Stowage and Securing - CSS Code. Detailed calculations of forces and moments related to lashings, which prevents non-standard cargo against transverse tipping, were performed. Some simplifications were proven that may result in underestimating or overstating the calculated righting moment, which decides of safety margin of securing non-standard cargoes. The alternative more reliable procedure, without simplifications, was proposed.
\end{abstract}

Keywords: safety of transportation; stowing; cargo securing; non-standard cargoes; lashing

\section{INTRODUCTION}

Stowing general cargoes on ships contains several operations associated with appropriate location of the cargoes and their securing. Contemporary technology used in cargo shipping aims at elimination of stowing errors by standardizing cargo units as well as appropriate adjusting ship structures. It makes it possible to expand automation of cargo handling in ports. The most popular have become containers which have dominated cargo transport by sea. Technology of handling and securing containers on ships makes it possible to entirely eliminate workforce and achieve this way very high effectiveness. Several millions of containers are yearly handled in sea container terminals which employ a few dozen percent smaller number of workers as compared with traditional general cargo terminals. This constitutes a huge technological progress but it also posseses its own limitations. A part of cargoes, called non-standard ones, requires - and will require in the future - an individual approach and significant human work outlay. Among them heavy cargo pieces, large gabarite loads as well as other loads in non-standard packing, are numbered.

Stowing techniques of non-standard cargoes are rarely described in ship cargo handling documentation, especially in Cargo Securing Manual. Therefore persons responsible for loading are forced to rely on other available documents and their knowledge of ship, cargo and own experience. Their responsibility is high as stowing errors are often associated with high cargo losses and in extreme cases they can cause loss of ship's floatability. The principle is that each piece of non-standard cargo requires seperate stowing calculations and selection of a suitable securing technique with the use of appropriate lashing equipment. Appropriate know-how in the area is crucial.

In present there are a few IMO (Internatonal Maritime Organisation) documents useful in preparing stowing plans for non-standard cargoes. Code of Safe Practice for Cargo Stowage and Securing - CSS Code is the most important. The Code contains example procedures for stowing calculations, which make it possible to select proper securing equipment. In 2002 during 75th session of MSC/IMO subcommitee some important changes were introduced to Appendix13, titled „Methods to assess the efficiency of securing arrangements for nonstandardized cargoes". In the Appendix formulae and tables are included for calculation of forces intended to protect against shifting and overturning a non-standard cargo. Knowledge of such forces makes it possible to select an appropriate number and quality of securing stays.

However the formulae and tables given in the Appendix in question contain some relatively important simplifications which affect results of calculations, that may result in lowering effectiveness of securing the cargo. The simplifications concern calculations for determination of forces occurring in stays intended to protect cargo against transverse overturning. The below presented analysis is aimed at making comparison of accuracy of calculations performed with the use of the CSS Code procedures and alternative ones. 
CALCULATIONS OF MOMENTS IN STAYS WHICH SECURE NON-STANDARD CARGO AGAINST TRANSVERSE OVERTURNING

The CSS Code recommends to use the below given inequality to control whether the cargo securing stays protect it against overturning in port or starboard direction :

$$
\begin{gathered}
\mathrm{F}_{\mathrm{y}} \cdot \mathrm{d} \leq \mathrm{b} \cdot \mathrm{m} \cdot \mathrm{g}+ \\
+0.9 \cdot\left(\mathrm{CS}_{1} \cdot \mathrm{c}_{1}+\mathrm{CS}_{2} \cdot \mathrm{c}_{2}+\ldots .+\mathrm{CS}_{\mathrm{n}} \cdot \mathrm{c}_{\mathrm{n}}\right)
\end{gathered}
$$

where:

$$
\mathrm{F}_{\mathrm{y}} \quad-\text { transverse cargo overturning force }[\mathrm{kN}]
$$

$\mathrm{d}^{\mathrm{y}} \quad-$ arm of action of overturnig force [m] (usually assumed equal to a half of the cargo height $\mathrm{d}=\mathrm{h} / 2$ )

$\mathrm{b}=\mathrm{e} / 2$ [m], [where: $\mathrm{e}-$ transverse distance between supports of a cargo (cargo breadth)]

$\mathrm{m} \quad-$ mass of a cargo unit [t]

$\mathrm{g}=9.81 \mathrm{~m} / \mathrm{s}^{2}$ (gravity acceleration)

$\mathrm{CS}_{1}, \mathrm{CS}_{2}, \ldots . \mathrm{CS}$ - forces in stays

$\mathrm{c}_{1}, \mathrm{c}_{2}, \ldots . . \mathrm{c}_{\mathrm{n}} \quad \mathrm{C}_{\mathrm{n}}-$ arms of action of forces in stays.

The important assumption given in the CSS Code indicates that the angles $\alpha$ and $\beta$, between the stay and ship's deck, (the vertical angle $\alpha$ between and perpendicular to ship central line, and the horizontal angle $\beta$ ) are to satisfy the following requirement (Fig. 1): $\alpha \geq 45^{\circ}$ or $\beta \leq 45^{\circ}$.

Additionally, forces in stays are calculated as a fraction of the maximum securing load MSL according to the formula:

$$
\mathrm{CS}=\frac{\mathrm{MSL}}{1.35}[\mathrm{kN}]
$$

The CSS Code also indicates a way to simplification of calculations by making assumption that values of arms of forces in stays are approximately equal to the cargo breadth e:

$$
\mathrm{c}_{1} \approx \mathrm{c}_{2} \approx \ldots \ldots \approx \mathrm{c}_{\mathrm{n}} \approx \mathrm{e}
$$

Hence the inequality (1) can be substituted by the following:
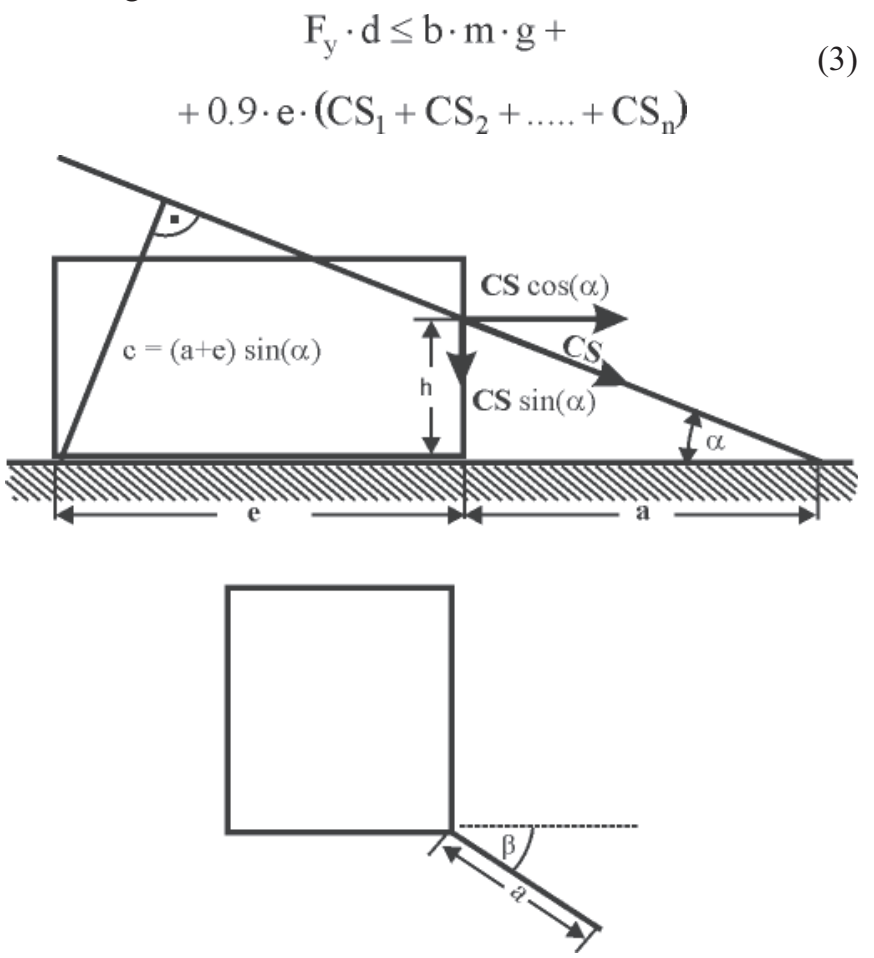

Fig. 1. Moment of single stay which prevents against cargo overturning (According to the authors' elaboration).
Course of calculations which led to formulation of the inequality (3) which describes forces acting in the case of transverse overturning the cargo, can be analyzed by using simple calculations. The inequality illustrates the relation between the cargo overturning moment which acts crosswise the ship and the moment which resist the former. This is the moment associated with action of the gravity force $\mathrm{m} \cdot \mathrm{g}$ and sum of the moments associated with forces in oblique cargo securing stays, $M_{y}$. The stays must be directed towards the opposite side relative to direction of action of the overturning force.

$$
\mathrm{F}_{\mathrm{y}} \cdot \mathrm{d} \leq \mathrm{b} \cdot \mathrm{m} \cdot \mathrm{g}+\mathrm{M}_{\mathrm{y} 1}+\mathrm{M}_{\mathrm{y} 2}+\ldots+\mathrm{M}_{\mathrm{yn}}
$$

The moment of force in single stay, which resist the overturning, is equal to:

$$
\mathrm{M}_{\mathrm{y}}=\mathrm{CS} \cdot \mathrm{c}=\mathrm{CS} \cdot(\mathrm{a}+\mathrm{e}) \cdot \sin \alpha
$$

where:

$\mathrm{CS}$ - force in single stay $[\mathrm{kN}]$

c - arm of force [m]

a - vertical projection of the stay line onto the deck plane [m].

The formula is correct only for the angle $\beta$ equal to $0^{\circ}$ (i.e. when the stay is perpendicular to ship's central plane). Otherwise, at determining the moment $\mathrm{M}_{\psi}$, the parameter a should be substituted by the product $a \cdot \cos \beta$, and the formula in question finally takes the form as follows (Fig. 2) :

$$
\mathrm{M}_{\mathrm{y}}=\mathrm{CS} \cdot(\mathrm{e}+\mathrm{a} \cdot \cos \beta) \cdot \sin \alpha
$$

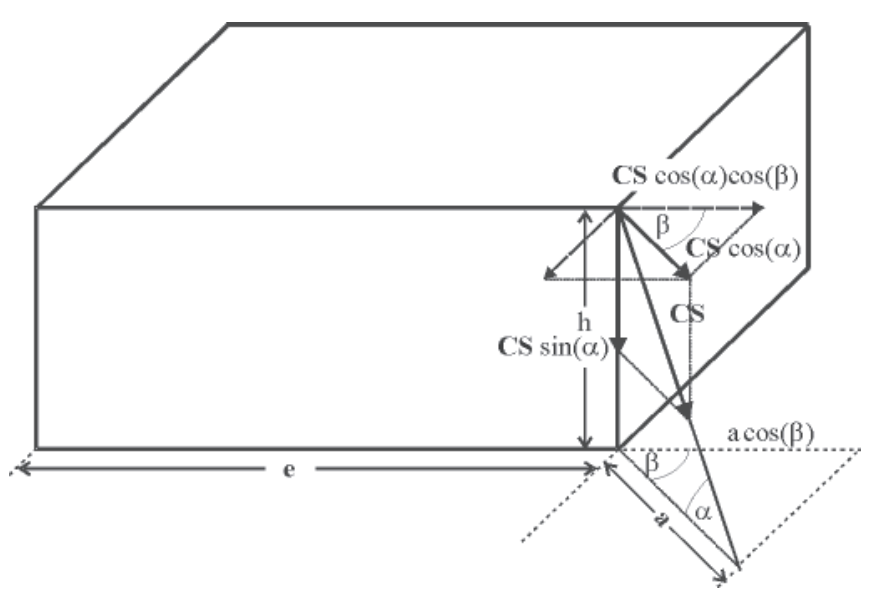

Fig. 2. Decomposition of the force acting in stay which resist the overturning of cargo (According to the authors'elaboration).

On substitution of a by :

$$
\mathrm{a}=\frac{\mathrm{h}}{\operatorname{tg} \alpha}
$$

the following was obtained:

$$
\begin{aligned}
& \mathrm{M}_{\mathrm{y}}=\mathrm{CS} \cdot \sin \alpha \cdot\left(\mathrm{e}+\frac{\mathrm{h}}{\operatorname{tg} \alpha} \cdot \cos \beta\right)= \\
& =\mathrm{CS} \cdot \mathrm{e} \cdot \sin \alpha \cdot\left(1+\frac{\mathrm{R}}{\operatorname{tg} \alpha} \cdot \cos \beta\right)=
\end{aligned}
$$

$=\mathrm{CS} \cdot \mathrm{e} \cdot(\sin \alpha+\mathrm{R} \cdot \cos \alpha \cdot \cos \beta)=\mathrm{CS} \cdot \mathrm{e} \cdot \mathrm{fm}_{\mathrm{y}}$

where:

$$
\mathrm{M}_{\mathrm{y}}=\mathrm{CS} \cdot \mathrm{e} \cdot \mathrm{fm}_{\mathrm{y}}
$$

$\alpha-$ vertical angle of stay

$\beta-$ horizontal angle of stay 
- ratio of the stay's fixing point height $h$ and the cargo breadth $\mathrm{e}, \mathrm{h} / \mathrm{e}$

$\mathrm{fm}_{\mathrm{y}}=\sin \alpha+\mathrm{R} \cdot \cos \alpha \cdot \cos \beta-$ a coefficient.

On introduction of the developed form of the parameter $\mathrm{M}_{\mathrm{y}}$ into the inequality (3) it takes the form:

$$
\begin{gathered}
\mathrm{F}_{\mathrm{y}} \cdot \mathrm{d} \leq \mathrm{b} \cdot \mathrm{m} \cdot \mathrm{g}+ \\
+\mathrm{e} \cdot\left(\mathrm{CS}_{1} \cdot \mathrm{fm}_{\mathrm{y}_{1}}+\mathrm{CS}_{2} \cdot \mathrm{fm}_{\mathrm{y}_{2}}+\ldots .+\mathrm{CS}_{\mathrm{n}} \cdot \mathrm{fm}_{\mathrm{y}_{\mathrm{n}}}\right)
\end{gathered}
$$

By making use of the relation (4) the table was elaborated which serves to determine the coefficient $\mathrm{fm}_{\mathrm{y}}$ for various values of $\mathrm{R}$ and the stay angles $\alpha$ and $\beta$.

\begin{tabular}{|c|c|c|c|c|c|c|c|c|c|}
\hline & ${ }_{\beta} a$ & -30 & -10 & 0 & 10 & 30 & 50 & 70 & 90 \\
\hline \multirow{5}{*}{ I } & 10 & 0.35 & 0.80 & 0.98 & 1.14 & 1.35 & 1.40 & 1.28 & 1.00 \\
\hline & 30 & 0.25 & 0.68 & 0.87 & 1.03 & 1.25 & 1.32 & 1.24 & 1.00 \\
\hline & 50 & 0.06 & 0.46 & 0.64 & 0.81 & 1.06 & 1.18 & 1.16 & 1.00 \\
\hline & 70 & -0.20 & 0.16 & 0.34 & 0.51 & 0.80 & 0.99 & 1.06 & 1.00 \\
\hline & 90 & -0.50 & -0.17 & 0.00 & 0.17 & 0.50 & 0.77 & 0.94 & 1.00 \\
\hline \multirow{5}{*}{$\begin{array}{l}\stackrel{1}{\Perp} \\
\simeq\end{array}$} & 10 & 0.52 & 0.99 & 1.18 & 1.34 & 1.52 & 1.53 & 1.34 & 1.00 \\
\hline & 30 & 0.40 & 0.85 & 1.04 & 1.20 & 1.40 & 1.43 & 1.30 & 1.00 \\
\hline & 50 & 0.17 & 0.59 & 0.77 & 0.93 & 1.17 & 1.26 & 1.20 & 1.00 \\
\hline & 70 & -0.14 & 0.23 & 0.41 & 0.58 & 0.86 & 1.03 & 1.08 & 1.00 \\
\hline & 90 & -0.50 & -0.17 & 0.00 & 0.17 & 0.50 & 0.77 & 0.94 & 1.00 \\
\hline \multirow{5}{*}{$\begin{array}{l}\stackrel{+}{\sim} \\
\stackrel{\|}{\|} \\
\simeq\end{array}$} & 10 & 0.69 & 1.18 & 1.38 & 1.53 & 1.69 & 1.65 & 1.41 & 1.00 \\
\hline & 30 & 0.55 & 1.02 & 1.21 & 1.37 & 1.55 & 1.55 & 1.35 & 1.00 \\
\hline & 50 & 0.28 & 0.71 & 0.90 & 1.06 & 1.28 & 1.34 & 1.25 & 1.00 \\
\hline & 70 & -0.09 & 0.30 & 0.48 & 0.65 & 0.91 & 1.07 & 1.10 & 1.00 \\
\hline & 90 & -0.50 & -0.17 & 0.00 & 0.17 & 0.50 & 0.77 & 0.94 & 1.00 \\
\hline \multirow{5}{*}{ 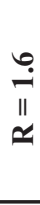 } & 10 & 0.86 & 1.38 & 1.58 & 1.73 & 1.86 & 1.78 & 1.48 & 1.00 \\
\hline & 30 & 0.70 & 1.19 & 1.39 & 1.54 & 1.70 & 1.66 & 1.41 & 1.00 \\
\hline & 50 & 0.39 & 0.84 & 1.03 & 1.19 & 1.39 & 1.43 & 1.29 & 1.00 \\
\hline & 70 & -0.03 & 0.37 & 0.55 & 0.71 & 0.97 & 1.12 & 1.13 & 1.00 \\
\hline & 90 & -0.50 & -0.17 & 0.00 & 0.17 & 0.50 & 0.77 & 0.94 & 1.00 \\
\hline \multirow{5}{*}{$\begin{array}{l}\stackrel{\infty}{\sim} \\
\stackrel{\infty}{\|} \\
\simeq\end{array}$} & 10 & 1.04 & 1.57 & 1.77 & 1.92 & 2.04 & 1.91 & 1.55 & 1.00 \\
\hline & 30 & 0.85 & 1.36 & 1.56 & 1.71 & 1.85 & 1.77 & 1.47 & 1.00 \\
\hline & 50 & 0.50 & 0.97 & 1.16 & 1.31 & 1.50 & 1.51 & 1.34 & 1.00 \\
\hline & 70 & 0.03 & 0.43 & 0.62 & 0.78 & 1.03 & 1.16 & 1.15 & 1.00 \\
\hline & 90 & -0.50 & -0.17 & 0.00 & 0.17 & 0.50 & 0.77 & 0.94 & 1.00 \\
\hline \multirow{6}{*}{$\begin{array}{l}\stackrel{\theta}{i} \\
\stackrel{1}{1} \\
\simeq\end{array}$} & 10 & 1.33 & 1.90 & 1.97 & 2.11 & 2.21 & 2.03 & 1.61 & 1.00 \\
\hline & 30 & 1.11 & 1.65 & 1.73 & 1.88 & 2.00 & 1.88 & 1.53 & 1.00 \\
\hline & 50 & 0.69 & 1.18 & 1.29 & 1.44 & 1.61 & 1.59 & 1.38 & 1.00 \\
\hline & 70 & 0.13 & 0.55 & 0.68 & 0.85 & 1.09 & 1.21 & 1.17 & 1.00 \\
\hline & 90 & -0.50 & -0.17 & 0.00 & 0.17 & 0.50 & 0.77 & 0.94 & 1.00 \\
\hline & $\beta / \alpha$ & -30 & -10 & 0 & 10 & 30 & 50 & 70 & 90 \\
\hline
\end{tabular}

Tab. 1. Values of the coefficient $f m_{y}$

(According to the authors' elaboration)

As indicates Tab. 1, the coefficient $\mathrm{fm}_{\mathrm{y}}$ take the values from the interval $[-0.50 ; 2.21]$. This is so much important that from comparison of the inequalities (2) and (5) results that the value of the coefficient $\mathrm{fm}_{\mathrm{y}}$, used in the procedure of the CSS Code is equal to 0.9. Even if the Code's limitations of applicability of its procedures to values of the angles $\alpha$ and $\beta$ $\left(\alpha \geq 45^{\circ} \text { or } \beta \leq 45^{\circ}\right)^{1}$ are satisfied they are contained within the interval $[0.25 ; 2.21]$. It is worth to show how large practical importance the just demonstrated difference in values of the assumed coefficient, has.

The values of the coefficient $\mathrm{fm}_{\mathrm{y}}$, which satisfy the limitation of the CSS Code are presented in Tab. 1 on gray background.

\section{EXAMPLE CALCULATIONS}

In the CSS Code some example calculations complying with recommended procedures are shown. The example concerned securing the heavy cargo piece of $68 \mathrm{t}$ mass and the dimensions : height $\mathrm{h}=2.4 \mathrm{~m}$, breadth $\mathrm{e}=1.8 \mathrm{~m}$, under action of the external transverse force Fy $=312 \mathrm{kN}$. In the arrangement of securing stays application was assumed of 4 stays on each ship side, external two of which on each side (no.1, 4, 5 and 8) were of $\mathrm{CS}=80 \mathrm{kN}$, and the remaining four (internal) were of $\mathrm{CS}=67 \mathrm{kN}$ (Fig. 3).

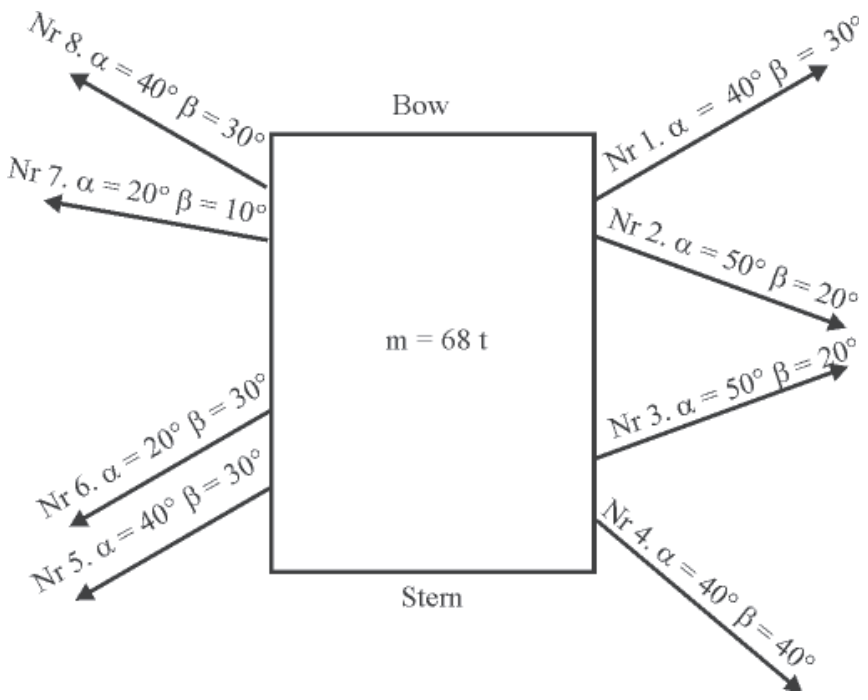

Fig. 3. Arrangement of stays to secure cargo piece (According to the authors' elaboration).

The calculations presented in the CSS Code with application of the inequality (2) yield the following result:

$$
\begin{gathered}
\mathrm{F}_{\mathrm{y}} \cdot \mathrm{d} \leq \mathrm{b} \cdot \mathrm{m} \cdot \mathrm{g}+0.9 \cdot \mathrm{e}\left(\mathrm{CS}_{1}+\mathrm{CS}_{2}+\mathrm{CS}_{3}+\mathrm{CS}_{4}\right) \\
312 \cdot 2.4 / 2 \leq 68 \cdot 9.81 \cdot 1.8 / 2+ \\
+0.9 \cdot 1.8 \cdot(80+67+67+80) \\
374 \leq 600.4+476.3 \\
374 \leq 1076.7
\end{gathered}
$$

The inequality is satisfied and takes the same form for both ship sides. It means that the applied securing system with the use of stays is sufficient to resist the cargo overturning force.

On the basis of the same data similar calculations with the use of the inequality (5) and the coefficients fm can be performed. For comparison the calculations based on the initial inequality (3) with the use of the expression $\mathrm{M}_{\mathrm{y}}=\mathrm{CS}(\mathrm{e}+\mathrm{a} \cos \beta) \sin \alpha$, were performed. The latter calculations are more exact as they are free of errors involved by reading values of the coefficient $\mathrm{fm}_{\mathrm{y}}$ from the table.

\section{Calculations for starboard side}

$$
\mathrm{R}=\mathrm{h} / \mathrm{e}=2.4 / 1.8=1.3
$$

The calculations with taking into account the coefficients $\mathrm{fm}_{\mathrm{y}}$ yield the following relationship:

$$
\begin{gathered}
\mathrm{F}_{\mathrm{y}} \cdot \mathrm{d} \leq \mathrm{b} \cdot \mathrm{m} \cdot \mathrm{g}+\mathrm{e}\left(\mathrm{CS}_{1} \cdot \mathrm{fm}_{\mathrm{y} 1}\right. \\
\left.+\mathrm{CS}_{2} \cdot \mathrm{fm}_{\mathrm{y} 2}+\ldots+\mathrm{CS}_{\mathrm{n}} \cdot \mathrm{fm}_{\mathrm{yn}}\right) \\
374 \leq 600.4+1.8 \cdot 434.4 \\
\quad 374 \leq 1382.3
\end{gathered}
$$


The exact calculations, i.e. without simplifications, yield the following relationship:

$$
\begin{gathered}
\mathrm{F}_{\mathrm{y}} \cdot \mathrm{d} \leq \mathrm{b} \cdot \mathrm{m} \cdot \mathrm{g}+\mathrm{M}_{\mathrm{y} 1}+\mathrm{M}_{\mathrm{y} 2}+\ldots+\mathrm{M}_{\mathrm{yn}} \\
374 \leq 600.4+804.0 \\
374 \leq 1404.4
\end{gathered}
$$

\begin{tabular}{|c|c|c|c|c|c|c|c|c|}
\hline $\begin{array}{l}\frac{\vec{J}}{0} \\
\frac{0}{0} \\
\dot{0} \\
\dot{0}\end{array}$ & $U^{\infty}$ & 8 & $\infty$ & $\underbrace{\stackrel{D}{\infty}}_{\pi}$ & 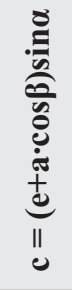 & $\stackrel{\dot{E}^{\prime \prime}}{\dot{U}^{-}}$ & $\Xi$ & $\stackrel{\Xi}{\dot{E}}^{\Xi^{\prime}}$ \\
\hline 1 & 80 & 40 & 30 & 2.86 & 2.75 & 220.0 & 1.48 & 118.4 \\
\hline 2 & 67 & 50 & 20 & 2.01 & 2.83 & 189.6 & 1.54 & 103.2 \\
\hline 3 & 67 & 50 & 20 & 2.01 & 2.83 & 189.6 & 1.54 & 103.2 \\
\hline 4 & 80 & 40 & 40 & 2.86 & 2.56 & 204.8 & 1.37 & 109.6 \\
\hline & & & & & & 804.0 & & 434.4 \\
\hline
\end{tabular}

Tab. 2. Strength calculations for starboard side

(According to the authors' elaboration)

\begin{tabular}{|c|c|c|c|c|c|c|c|c|}
\hline $\begin{array}{l}\frac{\vec{J}}{0} \\
\frac{0}{0} \\
\dot{0} \\
\dot{z}\end{array}$ & $\tilde{U}$ & 8 & $\infty$ & 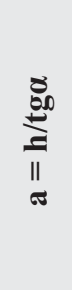 & 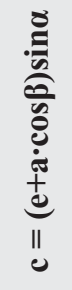 & $\stackrel{\dot{\dot{\omega}}}{\dot{U}^{\|}}$ & $\Xi^{2}$ & $\stackrel{\Xi}{\dot{m}}$ \\
\hline 5 & 80 & 40 & 30 & 2.86 & 2.75 & 220.0 & 1.48 & 118.4 \\
\hline 6 & 67 & 20 & 30 & 6.59 & 2.57 & 172.2 & 1.38 & 92.5 \\
\hline 7 & 67 & 20 & 10 & 6.59 & 2.83 & 189.6 & 1.47 & 98.5 \\
\hline 8 & 80 & 40 & 30 & 2.86 & 2.75 & 220.0 & 1.48 & 118.4 \\
\hline & & & & & & 801.8 & & 427.8 \\
\hline
\end{tabular}

\section{Calculations for port side}

Tab. 3. Strength calculations for port side

(According to the authors' elaboration)

The calculations with taking into account the coefficients $\mathrm{fm}_{\mathrm{y}}$ yield the following relationship:

$$
\begin{gathered}
374 \leq 600.4+1.8 \cdot 427.8 \\
374 \leq 1370.4
\end{gathered}
$$

The exact calculations, i.e. without simplifications, yield the following relationship:

$$
\begin{gathered}
374 \leq 600.4+801.8 \\
374 \leq 1402.2
\end{gathered}
$$

The obtained inequalities for port and starboard side differ to each other only a little. All the results indicate that the applied securing system with the use of stays is sufficient to resist cargo overturning force. In all variants the securing safety margin, i.e. the difference between overturning moment and righting moment, is much greater than that calculated according to the CSS Code.

\section{CONCLUSIONS}

On the basis of the performed accuracy analysis of strength calculations of securing the non-standard cargoes with the use of stays the following detail conclusions can be offerred:

The procedure for calculations of the moment resisting the transverse force which tends to overturn the non-standard cargo, recommended by the CSS Code, is simple in use but loaded by a large error resulting from the applied simplifications.

The first important simplification in the CSS Code is the application of the constant coefficient equal to 0,9 in the inequality (1) whereas in reality it takes values from the interval $[-0.50 ; 2.21]$.

Succesive simplification introduced in the CSS Code is the asssumption that values of arms of forces acting in stays are approximately equal to the cargo breadth $e$, that results in the recommendation on using the inequality (2) to calculations.

O Applicability of the CSS Code procedures is limited only to the stays the angles $\alpha$ and $\beta$ of which, formed by stay and deck and the line perpendicular to ship's central line, are to satisfy the requirement : $\left(\alpha \geq 45^{\circ}\right.$ or $\left.\beta \leq 45^{\circ}\right)$; in practice the limitation eliminates certain stowing techniques.

In the presented example calculations the application of the asummed CSS Code simplifications results in lowering, by about $300 \mathrm{kNm}$, real value of the moment resisting the transverse force which tends to overturn a non-standard cargo piece; this may be compared with neglection of the force acting in one stay at least.

In practice, the application of the CSS Code procedures may be connected with lowering or overstating the calculated moment as the procedure takes into account only number and nominal strength of stays and does not differentiate them regarding the angle which they form with ship's deck and straight line perpendicular to ship's central line.; this is why the same result was obtained for the same number of stays on port and starboard side.

Application of the inequality (5) together with Tab. 1 which serves to determine the coefficient $\mathrm{fm}_{\mathrm{y}}$ for various values of $R$ and the angles $\alpha$ and $\beta$ of securing stays, is proposed as an alternative procedure for calculation of moments in stays which prevent the non-standard cargo from overturning, which is free of errors of excessive simplifications. Results obtained by means of the procedure only a little differ from those accurate calculated with the use of trigonometric functions. The observed differences result from application of linear interpolation to reading values of the coefficient $\mathrm{fm}_{\mathrm{y}}$ from Tab. 1, whereas in reality values of the coeffcient vary non-linearly.

Application of the alternative procedure should not be limited to any range of the angles $\alpha$ and $\beta$ formed by stays. However it is important to observe that for certain stays which are characterized by negative values of the angle $\alpha$, force in such stays, instead to prevent the cargo against transverse overturning, can co-operate with the overturning force. It can so happen if the coefficient $\mathrm{fm}_{\mathrm{y}}$ takes negative values. Therefore as a rule the system of securing the cargo by means of stays directed upwards from the level of their fixing points at the cargo, should be avoided. 
The proposed alternative procedure would improve safety of securing non-standard cargoes. Accurate calculations of moments resisting transverse overturning the cargo would be transformed to stowing decisions, i.e choice of number and strength of stays as well as a way of their fixing. As a result of this, errors in the form of unnecessary increasing the safety margin of cargo securing would be avoided, that is connected with additional labour consumption and cost of stowing. Moreover, the procedure makes it possible to avoid errors of lowering the safety margin which may result in overturning the cargo and further consequences.

\section{BIBLIOGRAPHY}

1. Code of Safe Practice for Cargo Stowage and Securing (CSS Code), International Maritime Organization (IMO IA292E), 2003

2. Guidelines For The Preparation Of The Cargo Securing Manual, International Maritime Organization (IMO I298E), 1997.

\section{CONTACT WITH THE AUTHORS}

Bogusz Wiśnicki, Ph. D. Maritime University of Szczecin Wały Chrobrego 1-2 70-500 Szczecin, POLAND e-mail: b.wisnicki@am.szczecin.pl 